\title{
Renal Nerve Blunts Natriuretic and Diuretic Response to Atrial Natriuretic Peptide in Conscious Rabbits
}

\author{
Hironobu Morita, Yasuhiro Nishida, Kenji Kangawa, ${ }^{*}$ \\ Naoto Minamino, ${ }^{*}$ Hisayuki Matsuo, ${ }^{*}$ and Hiroshi Hosomi \\ Department of Physiology, Kagawa Medical School, \\ Miki-cho, Kagawa, 761-07 Japan \\ * Department of Biochemistry, Miyazaki Medical College, \\ Miyazaki, 889-16 Japan
}

\begin{abstract}
The contribution of the renal nerve to the natriuretic and diuretic responses to rat atrial natriuretic peptide (rAMP) was investigated in conscious rabbits with unilateral renal denervation. Renal nerve activity (RNA) was measured at the contralateral innervated kidney. Catheters were bilaterally implanted into the ureters. Urine samples were collected from each kidney by gravity drainage at 10 -min clearance intervals. In rabbits with all baroreflexes intact, infusion of $\mathrm{rANP}$ at $0.3 \mu \mathrm{g} /(\mathrm{kg} \cdot \mathrm{min})$ for 30 min decreased mean arterial pressure by $8 \pm 4 \mathrm{mmHg}$ and increased RNA by $53 \pm 13 \%$. After sinoaortic baroreceptor denervation (SAD), hypotensive response to infusion of rANP was greater than that in intact rabbits, while RNA did not change. After SAD plus vagotomy, infusion of rANP lowered mean arterial pressure by $21 \pm 4 \mathrm{mmHg}$ and RNA by $19 \pm 6 \%$. In the denervated kidney, infusion of rANP increased $\mathrm{Na}^{+}$ excretion by $16.1 \pm 4.5$ from $3.5 \pm 1.0 \mu \mathrm{Eq} / \mathrm{min}$ and water excretion by $0.17 \pm 0.05$ from $0.08 \pm 0.02 \mathrm{ml} / \mathrm{min}$. In the contralateral innervated kidney, infusion of rANP increased the amount of $\mathrm{Na}^{+}$and water excretion by $4.5 \pm 3.2 \mu \mathrm{Eq} / \mathrm{min}$ and $0.07 \pm 0.04 \mathrm{ml} / \mathrm{min}$, which were significantly less than those in the denervated kidney. These results indicate that infusion of rANP increases RNA, due to baroreceptor reflexes, and that this increase in RNA blunts natriuretic and diuretic action of rANP.
\end{abstract}

Key words: renal nerve activity, atrial natriuretic peptide, vagus nerve, sinoaortic baroreceptor, natriuresis.

Atrial natriuretic peptide (ANP) is a hormone secreted from mammalian atria and is known for its potent natrituretic, diuretic, and renal vasodilator actions (Oshima et al., 1984; WinQuist et al., 1984; Hintze et al., 1985; HuANG et al., 1985; WAKITANI et al., 1985; HiNTzE, 1988). It is generally accepted that renal nerve 
activity (RNA) has a direct effect on the control of renal blood flow and urinary $\mathrm{Na}^{+}$excretion. Thus, it is hypothesized that increases in renal blood flow and urinary $\mathrm{Na}^{+}$excretion induced by intravenous administration of ANP is due to a decrease in RNA. However, responses of RNA to ANP infusion are still controversial KOYAMA et al. (1986) demonstrated that the intravenous infusion of ANP increased RNA in anesthetized dogs; but after sinoaortic baroreceptor denervation (SAD) plus vagotomy, ANP infusion decreased RNA. On the other hand THOREN et al. (1986) and IMAIZumi et al. (1987) demonstrated that ANP infusion decreased RNA in anesthetized rats with intact baroreflexes. However, THOREN et al. (1986) also demonstrated that ANP infusion produced a modest but significant increase in RNA in conscious rats. These controversial results were probably due to species difference and anesthetics. It should be noted that pentobarbital anesthesia decreased RNA in SAD rabbits and also decreased the sensitivity of RNA (MORITA et al., 1987). Thus, responses of RNA to ANP infusion is best studied in chronically instrumented conscious animals.

In this study, we examined the responses of RNA and renal function to intravenous ANP infusion in conscious rabbits. To further examine a role of RNA in augmentation of renal function induced by ANP infusion, urine flow and urinary $\mathrm{Na}^{+}$excretion were measured in conscious rabbits with unilateral renal denervation with catheters bilaterally inserted into each ureter. Thus, urine was separately collected from the innervated and the denervated kidney, and RNA was measured simultaneously. Because anesthesia modifies responses of RNA (MoRITA et al., 1987) and renal function (SADOWSKI et al., 1979), all experiments were carried out in chronically instrumented conscious rabbits.

\section{METHODS}

All experiments were conducted in 20 chronically instrumented conscious rabbits weighing $1.8-2.5 \mathrm{~kg}$. The animals were fed commercial rabbit food (Type ORC-4, Oriental Yeast Co.) at $100 \mathrm{~g} /$ day and water ad libitum. The animals were anesthetized with pentobarbital sodium $(30 \mathrm{mg} / \mathrm{kg}$ ) administered via the ear vein. The right $(n=5)$ or left $(n=4)$ kidney was exposed through a flask incision, and unilateral renal denervation was performed as described by DiBonA and SAWIN (1983), by stripping the renal vessels, ureter, and capsule of the kidney and coating with $5 \%$ phenol in $70 \%$ ethanol. One week after first surgery, a second surgery was performed using pentobarbital sodium $(30 \mathrm{mg} / \mathrm{kg})$ anesthesia. A venous catheter was placed into the superior vena cava via the right jugular vein for infusion of rat ANP (rANP). An arterial catheter was placed into the subclavian artery for measuring arterial pressure and collecting blood samples. The left $(n=5)$ or right $(n=4)$ kidney was exposed retroperitoneally through a left flank incision. Renal sympathetic nerves along the renal artery were isolated, and two stainless steel electrodes (A-M system, INC. \#7935) were placed around the nerves. The nerves and electrodes were fixed with silicone gel (Wacker silicone 604A and 604B) before 
closure. The electrodes and catheters were exteriorized through the back of the neck. Catheters were implanted into the ureters bilaterally through the inguinal region, and then the incision was closed. Rabbits were allowed to recover from the surgical stress for 2 days prior to the experiment.

Arterial pressure was measured by connecting the previously implanted catheter to a Statham P23ID transducer. Heart rate was measured using a cardiotachometer (San-Ei \#1321) triggered by pulse pressure. An electronic R-C filter with a 2-s time constant was used to derive mean arterial pressure. Electrical activity recorded from the renal nerves was amplified using an amplifier with a $50 \mathrm{~Hz}$ to $1 \mathrm{kHz}$ bandpass filter (Nihon Kohden AVB-10) and monitored by an oscilloscope (Nihon Kohden VC-10) and audiospeaker. The output from the amplifier was passed through a gate circuit to subtract baseline noise. The output from the gate circuit was rectified by an absolute value circuit. The rectified signal was integrated by an R-C circuit with a 2-s time constant. Since the integrated output was a function of RNA dependent on the area of the pulses received and their frequency, the output signal from the integrator was taken as a measure of overall RNA. To quantitate RNA, the values just before rANP infusion were considered to be $100 \%$.

All experiments were conducted in conscious rabbits placed in a box which loosely restricted their movement. Arterial pressure, heart rate, and RNA were monitored continuously. After the equilibration period, the 30 -min control period was started. An infusion of synthetic rANP at a rate of $0.3 \mu \mathrm{g} /(\mathrm{kg} \cdot \min )$ was carried out for $30 \mathrm{~min}$ and this was followed by the 30 -min recovery period. Urine was collected by gravity drainage at 10 -min clearance intervals through the bilaterally inserted catheters. Thus, urine samples from the innervated and the contralateral denervated kidney were collected separately. The urine $\mathrm{Na}^{+}$concentration was determined by a flame photometer (Hitachi \#750, Tokyo) and urinary $\mathrm{Na}^{+}$excretion was calculated as urine $\mathrm{Na}^{+}$concentration times urine flow.

To examine the role of sinoaortic and cardiopulmonary baroreceptors in the response of RNA of intravenous rANP infusion, RNA was also measured in conscious rabbits after sinoaortic baroreceptor denervation (SAD) and SAD plus vagotomy. SAD was performed by bilateral sectioning of the aortic depressor nerves and carotid sinus nerves, and by stripping the bifurcations of the common carotid arteries $(n=9)$. Completeness of the denervation was confirmed in the conscious state by an absence of bradycardia or tachycardia upon i.v. injection of a pressor or depressor agent. One week after SAD, catheters and renal nerve electrodes were implanted as described above. Two days after the implantation, intravenous infusion of rANP was carried out, measuring arterial pressure, heart rate, and RNA $(n=9)$. One day after the experiments in SAD rabbits, bilateral cervical vagotomy was performed under general anesthesia with a short-acting barbiturate, thiamylal sodium $(10 \mathrm{mg} / \mathrm{kg}$, i.v. $)$. Five to $8 \mathrm{~h}$ after vagotomy, the same protocol as the SAD rabbits was repeated in rabbits with SAD plus vagotomy $(n=8)$.

To examine the effect of pentobarbital anesthesia on the response of RNA to rANP infusion, rANP was infused into two pentobarbital-anesthetized rabbits. 
After pentobarbital sodium $(30 \mathrm{mg} / \mathrm{kg}$ ) was infused into the ear vein, venous and arterial catheters were inserted and renal nerve electrodes were implanted. Catheters and electrode were exteriorized and incisions were closed. After the surgical procedures, anesthesia was sustained with supplemental dose of pentobarbital sodium, and rabbits were allowed to stabilize for at least $1 \mathrm{~h}$, then infusion of rANP was begun. Two days after the first experiment, the same protocol was repeated in the conscious state.

All data were continuously measured and recorded on an FM magnetic tape recorder (TEAC \#SR-30) and played back on a multichannel recorder (San-Ei omnicorder $8 \mathrm{MI} 4)$. All values presented here are reported as means \pm S.E.M. For any variable, no differences between average values for different time intervals exist over the control period. Therefore, the average value of each variable or parameter measured at $30,20,10$, and $0 \mathrm{~min}$ before infusion of rANP was taken as control. Variables after rANP infusion were compared to the control value using two-way analysis of variance. When the $F$-ratio exceeded the critical value, Dunnet's multi-sample test was applied to test the significance of the difference between the mean of control values and the values at a given time during infusion. Paired and unpaired $t$-test was used to determine whether significant differences existed between intact and SAD, and between intact and SAD plus vagotomy at each point in time. A $p$ value of less than 0.05 was taken as the criterion for a significant difference.

\section{RESULTS}

Figure 1 shows typical responses of arterial pressure, heart rate, and RNA to the intravenous rANP infusion. Average responses in 9 rabbits are summarized in Fig. 2. The rANP infusion $(0.3 \mu \mathrm{g} /(\mathrm{kg} \cdot \mathrm{min})$ for $30 \mathrm{~min})$ elicited a small but significant decrease in mean arterial pressure by $8 \pm 1$ from $85 \pm 4 \mathrm{mmHg}$ at the end of infusion. Then mean arterial pressure gradually returned toward the control level and at $30 \mathrm{~min}$ after the end of infusion it was not significantly different from the control. Heart rate did not change until $20 \mathrm{~min}$ after the start of infusion but increased by $17 \pm 5$ from $245 \pm 16$ beats $/ \mathrm{min}$ at the end of infusion and still elevated at $30 \mathrm{~min}$ after the end of infusion. These hemodynamic changes were accompanied by a significant increase in RNA, i.e., RNA gradually increaded instantaneously with rANP infusion and reached a maximum value at 20-30 min after the start of rANP infusion (Fig. 2). During the recovery period, RNA gradually recovered toward the control level and at the end of the recovery period no significant change was observed $(+10 \pm 7 \%)$. Decrease in mean arterial pressure $(-26 \pm 4 \mathrm{mmHg})$ due to rANP infusion in SAD rabbits was greater than that in intact rabbits, while increases in heart rate and renal nerve activity were completely blocked, i.e., heart rate $(-3 \pm 3$ beats $/ \mathrm{min})$ and RNA $(+2 \pm 8 \%)$ were not changed by rANP infusion. After SAD plus vagotomy, rANP infusion decreased mean arterial pressure by $21 \pm 4$ from $102 \pm 7 \mathrm{mmHg}$, did not change heart rate $(-0 \pm 2$ beats $/ \mathrm{min})$, and significantly decreased RNA by $19 \pm 6 \%$. 


\section{Intact}

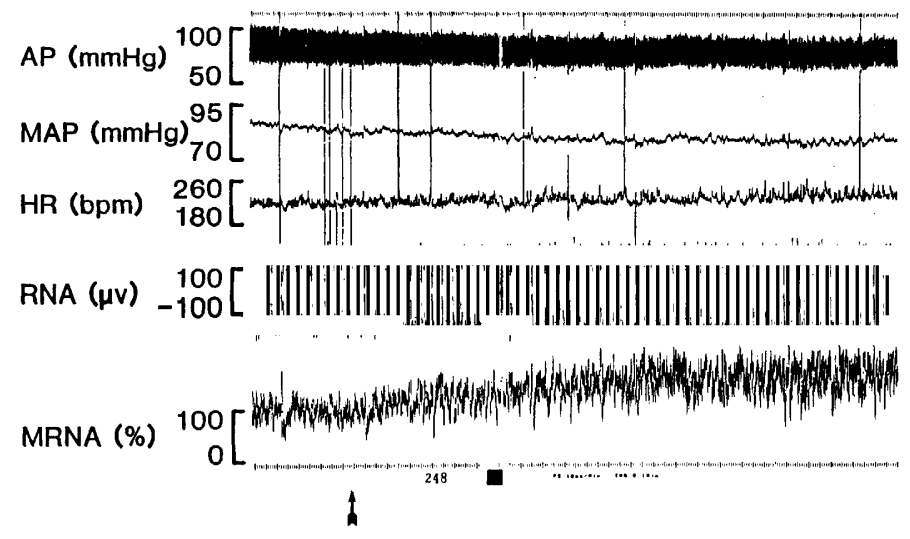

\section{SAD+vagotomy}

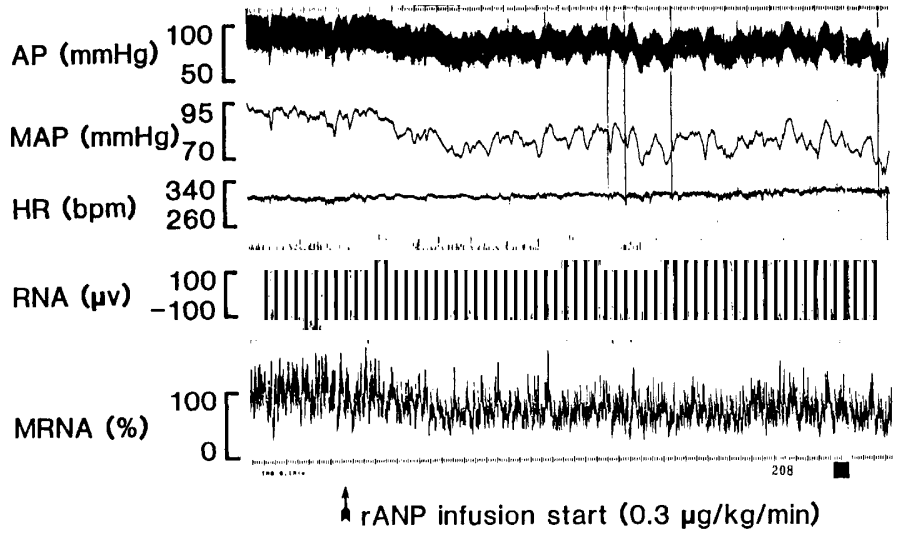

$5 \min$

Fig. 1. Original records illustrating responses of phasic arterial pressure (AP), mean arterial pressure (MAP), heart rate (HR), renal nerve activity (RNA), and mean renal nerve activity (MRNA) to intravenous infusion of rANP in a conscious rabbit with all baroreflexes intact (upper panel) and with sinoaortic baroreceptor denervation (SAD) plus vagotomy (lower panel). The arrow indicates the beginning or rANP infusion $(0.3 \mu \mathrm{g} /(\mathrm{kg} \cdot \mathrm{min})$ for $30 \mathrm{~min})$.

In two anesthetized rabbits, the decrease in mean arterial pressure was not different from that in conscious rabbits. However, the increase in RNA in response to rANP infusion was attenuated, i.e., RNA increased by 11 and $8 \%$ in anesthetized condition, while RNA increased by 50 and $71 \%$ in conscious condition.

The weight of the denervated kidney $(10.6 \pm 0.8 \mathrm{~g})$ was not significantly different from that of the contralateral innervated kidney $(10.9 \pm 1.1 \mathrm{~g})$. The control value of the urine flow from the denervated kidney $(0.075 \pm 0.017 \mathrm{ml} / \mathrm{min})$ was not 

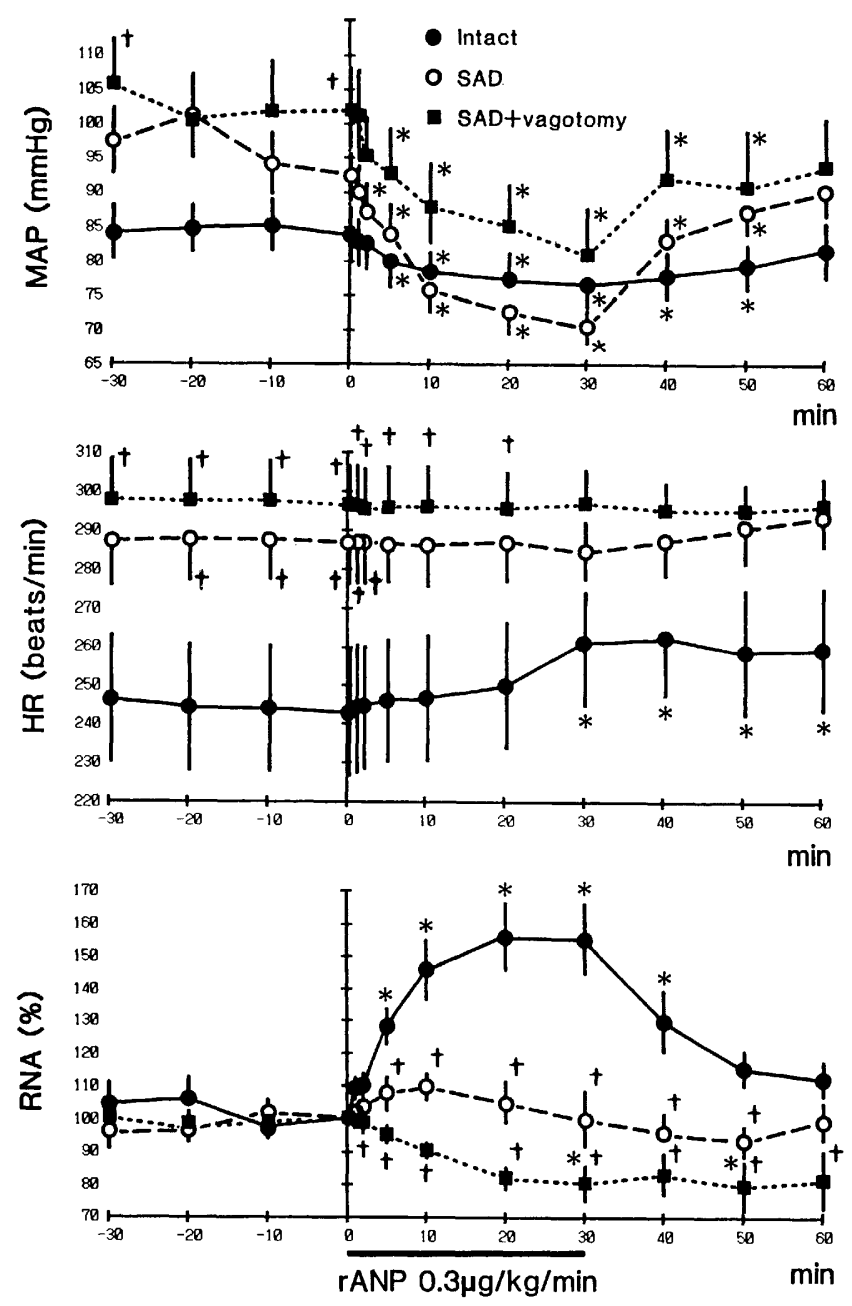

Fig. 2. Mean \pm S.E.M. of mean arterial pressure (MAP), heart rate (HR), and renal nerve activity (RNA) are shown in response to intravenous infusion of rANP $(0.3 \mu \mathrm{g} /(\mathrm{kg} \cdot \mathrm{min})$ for $30 \mathrm{~min}) . * p<0.05$, significantly different from the control. $+p<0.05$, significantly different from the intact group.

signiflcantly different from the contralateral innervated kidney $(0.057 \pm 0.012$ $\mathrm{ml} / \mathrm{min}$ ). However, the control value of the urine $\mathrm{Na}^{+}$excretion from the denervated kidney $(3.45 \pm 0.97 \mu \mathrm{Eq} / \mathrm{min})$ was significantly greater than that from the contralateral innervated kidney $(1.66 \pm 0.66 \mu \mathrm{Eq} / \mathrm{min})$. In the denervated kidney, diuresis and natriuresis occurred almost instantaneously with rANP infusion and reached a peak at the end of the infusion period (Fig. 3). However, the responses in the innervated kidney were quantitatively different from the responses in the 

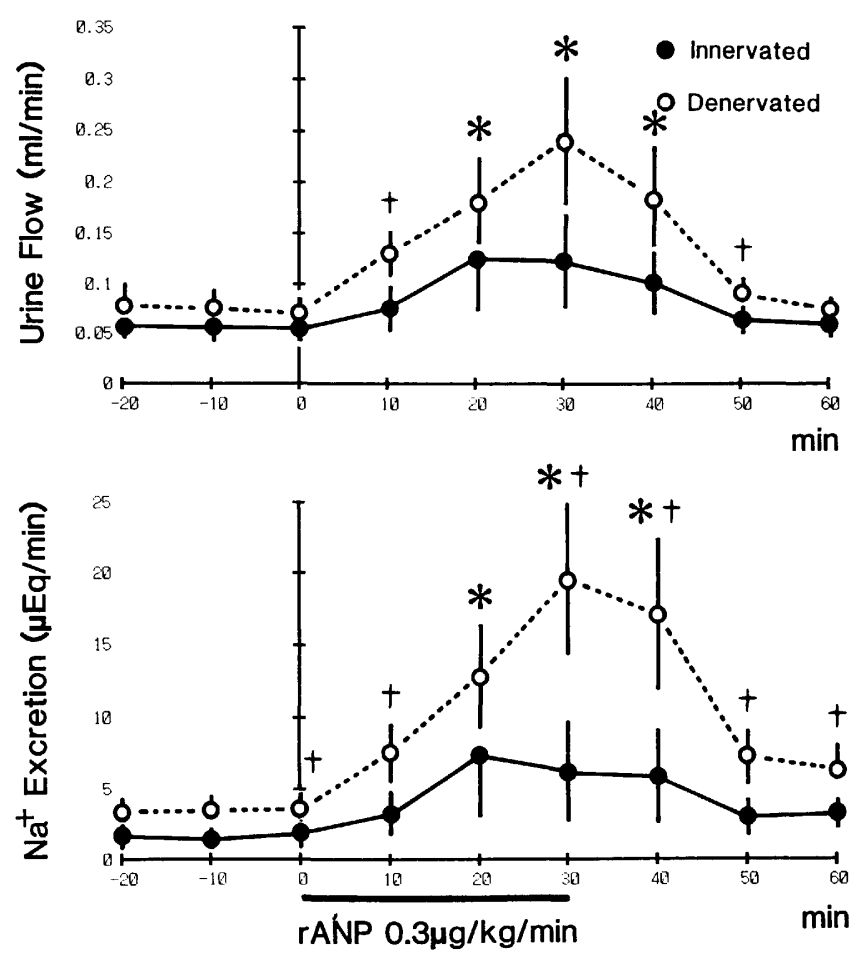

Fig. 3. Comparison of responses of urine flow and $\mathrm{Na}^{+}$excretion to intravenous rANP infusion $(0.3 \mu \mathrm{g} /(\mathrm{kg} \cdot \mathrm{min})$ for $30 \mathrm{~min})$ in conscious rabbits with unilateral renal denervation. Closed circles represent responses in the innervated kidney; open circles represent responses in the contralateral denervated kidney. $* p<0.05$, significantly different from the control. $\uparrow<0.05$, significantly different from the innervated kidney.

contralateral denervated kidney. During the infusion period, urine flow from the denervated kidney increased by $3.27 \pm 0.81 \mathrm{ml} / 30 \mathrm{~min}$, which was significantly larger than that from the innervated kidney $(1.54 \pm 1.01 \mathrm{ml} / 30 \mathrm{~min})$. In the denervated kidney, urinary $\mathrm{Na}^{+}$excretion increased by $0.29 \pm 0.08 \mathrm{mEq} / 30 \mathrm{~min}$, while in the innervated kidney urinary $\mathrm{Na}^{+}$excretion increased by $0.12 \pm 0.08 \mathrm{mEq} / 30 \mathrm{~min}$ $(p<0.05)$.

\section{DISCUSSION}

The major findings of the present study were: 1) rANP infusion decreases RNA in rabbits with SAD plus vagotomy, while rANP infusion increases RNA in intact rabbits, due to sinoaortic and cardiopulmonary baroreflexes; 2) the increase in RNA blunts diuretic and natriuretic responses to rANP infusion.

In intact rabbits, the fall of arterial pressure with rANP infusion was accompanied by the reflex increase in heart rate and RNA. The hypotensive effect 
of rANP infusion was enhanced significantly by SAD or SAD plus vagotomy. However, the increase in heart rate and RNA were completely blocked by SAD. These results indicate that the sinoaortic baroreceptors buffer the hypotension caused by rANP infusion and promote the increase in RNA. The location of ANP binding sites within the brain suggests that this peptide could modulate central nervous system regulation of sympathetic outflow and blood pressure (QuiRION et al., 1984; KURIHARA et al., 1987). In fact, intracerebroventricular injection of ANP stimulates the $\alpha_{2}$-adrenergic system in the central nervous system (LEVIN et al., 1988). This in turn might lead to decreased central sympathetic outflow. Furthermore, CHEUNG (1988) demonstrated that ANP depressed the excitability of the inferior mesenteric ganglion by decreasing the frequency of the action potentials, prolonging the afterpotential, and increasing the threshold of the action potentials. Thus ANP itself might decrease RNA. This is true in the present study, where without baroreflex buffering action infusion of rANP decreased RNA.

Although we did not measure left atrial pressure, left atrial pressure might be decreased by rANP infusion due to a decrease in body fluid and redistribution of body fluid (EBERT, 1988). The decrease in left atrial pressure unloads "low-pressure" cardiopulmonary baroreceptors and promotes an increase in RNA (MORITA and VATNER, 1985). Therefore, unaltered RNA in SAD rabbits may be a summed result of increased RNA by cardiopulmonary baroreflexes and decreased RNA by rANP itself. Thus, if there is no buffer action of sinoaortic and cardiopulmonary baroreceptors, rANP infusion decreases RNA.

THOREN et al. (1986) and IMAIzUMI et al. (1987) demonstrated that in anesthetized rats with intact baroreceptors, hypotension induced by ANP infusion did not cause the increase in RNA. However, THOREN et al. (1986) also demonstrated that in rats that had recovered from anesthesia, ANP infusion produced less of a decrease in arterial pressure than in anesthetized rats and the increase, in RNA. KOEPKE et al. (1987) demonstrated that RNA increased in conscious cirrhotic rats during ANP infusion and that increased RNA mediated the blunted diuretic and natriuretic responses to ANP infusion in conscious cirrhotic rats. However, RNA decreased during ANP infusion in conscious normal rats. The different result between their study and our study may be due to species difference and anesthetics. The performed conscious-state experiments $4-6 \mathrm{~h}$ after anesthesia, while at least 2 days elapsed before experiments in our study. In the present study, we also demonstrated that the increase in RNA was quite attenuated by surgical stress and anesthesia. Recently, EBERT (1988) demonstrated that in the conscious human, nonhypotensive infusions of ANP produced a reflex increase in muscle sympathetic efferent activity due to unloading of cardiopulmonary baroreceptors. These results indicate that under anesthetized condition, the buffering ability of baroreflexes should decrease. Because anesthesia itself alters sensitivities of baroreflex control of heart rate and RNA, the effects of ANP infusion on the autonomic nervous system are best studied under the chronically instrumented conscious condition (MORITA et al., 1987). 
An injection of ANP selectively increase renal blood flow (Hintze et al., 1985). However, during 1-h infusion of ANP, renal blood flow increased only transiently, then decreased below the control level (HINTZE, 1988). After $\alpha_{1}$-adrenergic receptor blockade, the initial renal vasodilation in response to ANP was prolonged (HINTZE, 1988), indicating that the secondary vasoconstriction was most likely due to a reflexly mediated sympathetic activation. Our data support this hypothesis, since infusion of rANP increased RNA in intact rabbits and decreased RNA in rabbits with SAD plus vagotomy. Although we did not measure renal blood flow, renal blood flow may decrease in intact rabbits and increase in rabbits with SAD plus vagotomy.

It has been clearly shown that the efferent renal sympathetic nerves are capable of directly influencing renal tubular $\mathrm{Na}^{+}$reabsorption independent of changes in systemic or renal hemodynamics. This is based on the following facts. First, low-level direct renal sympathetic nerve stimulation elicits a decrease in urinary $\mathrm{Na}^{+}$excretion without any changes in renal blood flow (DiBona, 1982). Second, acute renal denervation results in increased $\mathrm{Na}^{+}$excretion in the absence of changes in either arterial pressure or glomerular filtration rate (BENCSATH et al., 1985). Third, histochemical and autoradiographic studies have demonstrated adrenergic nerve terminals in direct contact with proximal and distal tubules (BARAJAS et al., 1984). These observations suggest that the increase in RNA induced by rANP infusion prevents natriuresis. That was the case in this study, as denervated kidneys excreted more $\mathrm{Na}^{+}$than innervated kidney. ANP can directly inhibit sodium absorption in isolated perfused cortical collecting ducts (NONOGUCHI et al., 1989). Although ANP is capable of decreasing the release of renin (SALAZAR et al., 1986), most of the natriuretic effect of ANP cannot be explained by a comparable reduction in the intrarenal level of angiotensin II (SALAZAR et al., 1987). Thus the natriuresis observed in the denervated kidney was probably due to the direct action of rANP to the collecting ducts, while small natriuresis observed in the innervated kidney was the sum of the natriuresis directly induced by rANP infusion and the antinatriuresis induced by baroreflexly increased RNA.

In conclusion, intravenous infusion of rANP increased RNA due to sinoaortic and cardiopulmonary baroreflexes and this increase in RNA blunts natriuretic and diuretic action of rANP.

This study was supported in part by a Research Grant for Cardiovascular Diseases 63C-2 from the Ministry of Health and Welfare of Japan and by a Grant-in-Aid for Scientific Research (No. 63480516) from the Ministry of Education, Science and Culture, Japan. Dr. Morita was supported by a Grant-in-Aid for Encouragement of Young Scientists of Japan (No. 63770060) and Japan Heart Foundation Research Grant for 1989.

\section{REFERENCES}

Barajas, L., Powers, K., and Wang, P. (1984) Innervation of the renal cortical tubules: 
A quantitative study. Am. J. Physiol., 247 (Renal Fluid Electrolyte Physiol., 16): F50-F60.

Bencsath, P., Szenasi, G., and Takacs, L. (1985) Water and electrolyte transport in Henle's loop and distal tubule after renal sympathectomy in the rat. Am. J. Physiol., 249 (Renal Fluid Electrolyte Physiol., 18): F308-F314.

Cheung, D. W. (1988) Atriopeptin III depresses the excitability of sympathetic neurones. Biochem. Biophys. Res. Commun., 154: 411-416.

DiBona, G. F. (1982) The functions of the renal nerves. Rev. Physiol. Biochem. Pharmacol., 94: 76-181.

DiBona, G. F. and SAwin, L. L. (1983) Renal nerves in renal adaptation to dietary sodium restriction. Am. J. Physiol., 245 (Renal Fluid Electrolyte Physiol., 14): F322-F328.

EBERT, T. J. (1988) Reflex activation of sympathetic nervous system by ANP in humans. Am. J. Physiol., 225 (Heart Circ. Physiol., 24): H685-H689.

HintZe, T. H. (1988) Significance of renal vasodilation after administration of atrial natriuretic factor in the conscious dog. Hypertension, 12: 143-151.

Hintze, T. H., Currie, M. G., and Needleman, P. (1985) Atriopeptines: Renal specific vasodilators in conscious dogs. Am. J. Physiol., 248 (Heart Circ. Physiol., 17): H587-H591.

Huang, C. L., Lewicki, J., Johnson, L. K., and Cogan, M. G. (1985) Renal mechanism of action of rat atrial natriuretic factor. J. Clin. Invest., 75: 769-773.

Imaizumi, T., Takeshita, A., Higashi, H., and Nakamura, M. (1987) $\alpha$-ANP alters reflex control of lumbar and renal sympathetic nerve activity and heart rate. Am. $J$. Physiol., 253 (Heart Circ. Physiol., 22): H1136-H1140.

KoEPKE, J. P., JoNES, S., and DiBona, G. F. (1987) Renal nerves mediate blunted natriuresis to atrial natriuretic peptide in cirrhotic rats. Am. J. Physiol., 252 (Regul. Intergr. Comp. Physiol., 21): R1019-R1023.

Koyama, S., Nishida, Y., Hosomi, H., and ABE, Y. (1986) Participation of baroreceptor reflexes in blood pressure and sympathetic nerve responses to a synthetic human atrial natriuretic peptide in anesthetized dogs. Eur. J. Pharmacol., 127: 43-48.

Kurihara, M., SaAvedra, J. M., and Shigematsu, K. (1987) Localization and characterization of atrial natriutic peptide binding sites in discrete areas of rat brain and pituitary gland by quantitative autoradiography. Brain Res., 408: 31-39.

Levin, E. R., Weber, M. A., and Mills, S. (1988) Atrial natriuretic factor-induced vasodepression occurs through central nervous system. Am. J. Physiol., 255 (Heart Circ. Physiol., 24): H616-H622.

Morita, H., Nishida, Y., Uemura, N., and Hosomi, H. (1987) Effect of pentobarbital anesthesia on renal sympathetic nerve activity in the rabbit. J. Auton. Nerv. Syst., 20: $57-64$.

Morita, H. and Vatner, S. F. (1985) Effects of hemorrhage on renal nerve activity in conscious dogs. Circ. Res., 57: 788-793.

Nonoguchi, H., SANDS, J. M., and KNePPER, M. A. (1989) ANF inhibits $\mathrm{NaCl}$ and fluid absorption in cortical collecting duct of rat kidney. Am. J. Physiol., 256 (Renal Fluid Electrolyte Physiol., 25): F179-F186.

Oshima, T., Currie, M. G., Geller, D. M., and Needleman, P. (1984) An atrial peptide is a potent renal vasodilator substance. Circ. Res., 54: 612-616

Quirion, R., Dalpe, M., De Lean, A., Gutkowska J., Cantin, M., and Genest, J. (1984) Atrial natriuretic factor (ANF) binding sites in brain and related structures. Peptides, 5: 1167-1172. 
SAdowski, J., KuRkus, J., and GelleRT, R. (1979) Denervated and intact kidney responses to saline load in awake and anesthetized dogs. Am. J. Physiol., 237 (Renal Fluid Electolyte Physiol., 6): F262-F267.

Salazar, F. J., Fiksen-Olsen, M. J., Opgenorth, T. J., Granger, J. P., Burnett, J. C., Jr., and Romero, J. C. (1986) Renal effects of ANP without changes in glomerular filtration rate and blood pressure. Am. J. Physiol., 251 (Renal Fluid Electrolyte Physiol., 20): F532-F536.

Salazar, F. J., Granger, J. P., Fiksen-Olsen, M. J., Bentley, M. D., and Romero, J. C. (1987) Possible modulatory role of angiotensin II on atrial peptide-induced natriuresis. Am. J. Physiol., 253 (Renal Fluid Electrolyte Physiol., 22): F880-F883.

Thoren, P., Mark, A. L., Morgan, D. A., O'neill, T. P., and Needleman, P., and Brody, M. J. (1986) Activation of vagal depressor reflexes by atriopeptins inhibits renal sympathetic nerve activity. Am. J. Physiol., 251 (Heart Circ. Physiol., 20): H1252-H1259.

Wakitani, K., Oshima, T., Loewy, A. D., Holmberg, S. W., Cole, B. R., Adams, S. P., FoK, K. F., Currie, M. G., and Needleman, P. (1985) Comparative vascular pharmacology of the atriopeptins. Circ. Res., 56: 621-627.

Winquist, R. J., Faison, E. P., Waldman, S. A., Schwartz, K., Murad, F., and Rapoport, R. M. (1984) Atrial natriuretic factor elicits an endothelium-independent relaxation and activates particulate guanylate cyclase in vascular smooth muscle. Proc. Natl. Acad. Sci. U.S.A., 81: 7661-7664. 